factors: not beginning early enough owing to inadequate provision of nursery schools or nursery classes for deaf children, and a tendency to isolate 'speech lessons' from 'language lessons'. In this book the Ewings propound a new approach, a 'genetic approach', to the teaching of speech to deaf children. They support their thesis by a comprehensive summary of new and proved methods used in the education of normal hearing children, and of the results of the many research projects carried out by them, or under their direction, in the University of Manchester.

Implicit in the 'genetic approach' is the belief that speech for the deaf child is primarily a form of mental growth, that it is a blossoming for which the mind and body are innately prepared, and will take place spontaneously in spite of the physical and mental handicap of deafness if a favourable social and emotional climate is provided. In a suitable environment, the first step is the development of a readiness for speech-a form of maturation analogous to 'reading readiness', and which, like it, takes place at different ages in different children. When a child is 'speech ready' the first words are produced spontaneously, indicating clearly that words are beginning to play a part in the life of his mind. They are the natural beginnings of speech as surely as are the first words of an ordinary child, and with assistance and guidance by a skilled teacher this speech can be developed until it becomes fluent and adequate for all normal purposes. Speech must be regarded as part of the normal life of the child, and all known means of developing it must be used. Auditory training has been proved to be of great value even for severely deaf children with hearing losses up to a hundred decibels.

The book is an excellent reference manual for all students and teachers of speech, and at the same time an encouragement to all parents and friends of deaf children. It is permeated with the inspiration and the firm belief in oral methods that Dr. Irene Ewing instilled into her students from the earliest days of the Department of Education of the Deaf in the University of Manchester, and it supports all that it claims by the production of living evidence. There will undoubtedly be a greater proportion of 'oral failures' than one would expect after reading the book, even after many years of practical application of the method described, and no doubt some readers will emphasize this point. The evidence given in the appendix also appears to be of a specific nature, and should be accepted with eaution; but personal experience has shown that the results are astonishing. This is probably the most important contribution to the education of the deaf during the present century.

R. Askew

\section{TIMBER DEVELOPMENT}

\section{Timber}

Its Structure and Properties. By Dr. H. E. Desch. Third edition. Pp. xxiv $+350+65$ plates. (London : Macmillan and Co., Ltd., 1953.) 25s. net.

$\mathrm{T}$ is a truism that increased efficiency in many 1 branches of industry depends not so much on the acquisition of new technical knowledge as on the application of existing knowledge. In the timberusing industries there is certainly scope for improving the standard of production by having regard to the basic facts and principles of timber technology. The information is available for those who are in a position to make use of it; but the original sources of information are widely scattered, and considerable time and trouble may be involved in acquiring the relevant publications and assimilating their contents. A text-book of timber technology such as the volume under review can be very useful, therefore, to architects, surveyors, building contractors and works managers, as also to students and others who can afford to buy only a limited number of books. Efforts to increase the productivity of under-developed forest areas will not be fully effective unless we have the skill and knowledge to utilize the timber efficiently. The presentation of technical information in a convenient form can contribute to the wellordered development of timber resources.

The author's primary object has been to provide the practical man with a simple, concise account of the structure, properties and methods of handling timber. The fact that a third edition has been called for so soon shows that the previous editions have been well received. In preparing the third edition the author has aimed at incorporating the more important results of research and development in the past five years. The text has been revised here and there, and new material has been added to the extent of sixty additional pages and ten more plates.

A feature of this new edition is a new chapter on the eradication of fungal and insect attack. It is generally agreed that decay and 'wood-worm' infestation in buildings are more prevalent to-day than formerly. This state of affairs has focused attention on insect and fungal pests of timber, and the publicity given to proprietary preservatives is tending to exaggerate the seriousness of the problem. The author has been at pains to analyse the alternative curative measures in an impartial manner. As he says, the three most common faults, when dealing with outbreaks of fungal attack, are to do too little investigation on the site, to carry out unnecessarily extensive replacements, and to ignore the fundamental cause, namely, a supply of moisture. Until the source of moisture is treced, the appropriate remedial measures cannot be laid down.

Although this book was originally written for the non-scientific reader, the author has had in mind also the needs of students preparing for examinations in timber technology. The sections on the classification of trees and the nomenclature of timbers have been rewritten in an attempt to clarify the difficulties laymen often experience with timber names. Some useful text-figures and plates illustrating structural features used in identification have been added. A note on the anisotropio swelling and shrinkage of wood, by R. D. Preston, has been included as an appendix to supplement the discussion of this subject in the body of the text. Having regard to recent advances in our knowledge of cell-wall structure, the author might have revised the section on the composition of the cell wall, which is based on what was known in 1938. With the advent of the electron microscope it is scarcely true to say, as is stated on p. 22 , that the gap between observations made by the light microscope and X-rays can only be filled by inference and conjecture.

At 25s. this book is remarkably good value, especially when it is realized that it is twice the size of the first edition, published in 1938 at $12 s .6 d$.

B. J. RENDLE 